\title{
Injury patterns in rural and urban Uganda
}

\author{
O Kobusingye, D Guwatudde, R Lett
}

\begin{abstract}
Objectives-To describe and contrast injury patterns in rural and urban Uganda. Settings-One rural and one urban community in Uganda.

Methods-Community health workers interviewed adult respondents in households selected by multistage sampling, using a standardized questionnaire.

Results-In the rural setting, 1673 households, with 7427 persons, were surveyed. Injuries had an annual mortality rate of 92/100 000 persons, and disabilities a prevalence proportion of $0.7 \%$. In the urban setting 2322 households, with 10982 people, were surveyed. Injuries had an annual mortality rate of $217 / 100000$, and injury disabilities a prevalence proportion of $2.8 \%$. The total incidence of fatal, disabling, and recovered injuries was $116 / 1000$ / year. Leading causes of death were drowning in the rural setting, and road traffic in the city.

Conclusion-Injuries are a substantial burden in Uganda, with much higher rates than those in most Western countries. The urban population is at a higher risk than the rural population, and the patterns of injury differ. Interventions to control injuries should be a priority in Uganda. (Injury Prevention 2001;7:46-50)
\end{abstract}

Keywords: trauma; pattern of injuries; Africa

The Global Burden of Disease Study estimates that $10 \%$ of global deaths are due to injuries, and that if current trends persist, this burden will greatly increase in the next 20 years. ${ }^{1}$ Reports like these suggest that the low income countries of Africa and Asia will have the heaviest burden. It is necessary to assess these predictions, because the implications are profound if they prove to be accurate.

In Uganda, most injury information is contained in police records, but this consists mostly of intentional and traffic injuries. Mortuary data have the same limitations and do not include non-fatal injuries. Consequently, we report results from an urban community survey, conducted in June 1997, and a rural survey, conducted in November 1998.

\section{Methods}

SETTINGS

Uganda is one of the East African great lakes countries, with the River Nile, several of its tributaries, and six large lakes located within its boundaries. Approximately $88 \%$ of the Ugandan population live in rural areas. ${ }^{2}$ Between 1985 and 1995, Uganda had a 220\% increase in licensed vehicles, and between 1992 and 1996, a $140 \%$ increase in vehicle ownershipthe highest in East Africa (Transport Research Laboratories UK, unpublished data).

Rural Uganda is characterized by subsistence farming, limited health care access, limited motorized transport, and a narrow range of economic activity. In contrast, urban settings have congested housing, better physical health care access, a wider range of economic activity, roads with busy vehicle and pedestrian traffic, but little provision for pedestrians and cyclists. These differences are likely to have different effects on the pattern of injury. Therefore, we selected Kawempe division, one of the five geopolitical divisions of Kampala city, and Mukono, a rural district in southern Uganda for this study.

Kawempe has approximately 200000 inhabitants. It has areas of dense urban slums, poorly demarcated trading centers, open markets along busy roads, light and medium industry, a tertiary level hospital, and a university campus.

Mukono has approximately 900000 inhabitants. About $12 \%$ of the population reside in small towns along a highway and the remainder is entirely rural. The district is served by five hospitals and a number of smaller health units. Access and use of formal health care are low, especially in areas where motorization is limited.

SAMPLING TECHNIQUES

In both settings, a three stage sampling procedure was used to identify the households needed to generate the required sample.

Urban setting

Stage I: the 18 parishes in Kawempe were divided into seven strata, based on population density. One parish was randomly selected from each stratum. Stage II involved randomly selecting $50 \%$ of the zones from each of the seven parishes. Using computer generated random numbers, 18 zones were selected. For stage III, beginning at the village meeting grounds, interviewers systematically selected households based on the required sample size for that village until the total was realized.

\section{Rural setting}

Stage I: the 30 subcounties in the district were grouped into seven strata by population density. One subcounty was randomly selected from each stratum, except for subcounties with population density $350+$ and 0-99. All subcounties with $350+$ persons $/ \mathrm{km}^{2}$ were small towns. Because of the likely difference in the pattern of injuries between towns and rural areas, two municipalities were purposely selected from this stratum. The sparsely populated subcounties (0-99 persons $\left./ \mathrm{km}^{2}\right)$ were on 
Table 1 Cause of injury by outcome: rural $(n=7427)$; results are number (\%)

\begin{tabular}{llll}
\hline Cause & $\begin{array}{l}\text { Fatal } \\
(n=34)\end{array}$ & $\begin{array}{l}\text { Disabling } \\
(n=55)\end{array}$ & $\begin{array}{l}\text { Recovered } \\
(n=575)\end{array}$ \\
\hline Traffic & $6(18)$ & $19(35)$ & $72(13)$ \\
Burns & $2(6)$ & $6(11)$ & $71(12)$ \\
Cuts/stabs & $4(6)$ & $9(16)$ & $197(34)$ \\
Blunt injury & $5(15)$ & $6(11)$ & $109(19)$ \\
Poison & $1(3)$ & 0 & $2(0.3)$ \\
Drowning & $9(27)$ & 0 & $3(0.5)$ \\
Animal bites & $2(6)$ & 0 & $29(5)$ \\
Falls & $1(3)$ & $13(24)$ & $73(13)$ \\
Gunshots & $2(6)$ & 0 & 0 \\
Other & $2(6)$ & $2(4)$ & $19(3)$ \\
\hline
\end{tabular}

the shores of lakes Kyoga and Victoria. We purposely selected two subcounties from this stratum. Stage II involved randomly selecting $50 \%$ of the villages in each subcounty and for stage III, interviewers started at the village meeting grounds, and selected households randomly until the required sample was realized. In every village at least 20 households were visited.

REQUIRED SAMPLE SIZE

Population estimates were obtained from the 1991 Population and Housing Census Report adjusted for projected population growth. ${ }^{3}$ Sample sizes were determined using a formula for cross sectional surveys, with a $95 \%$ confidence interval. ${ }^{4}$

Kawempe

Because of lack of information on the expected level of trauma in this area, we assumed that at most $50 \%$ of persons would sustain an injury annually, and allowed for a maximum error of $8 \%$ resulting in a minimum sample of 9947 . This was proportionately distributed among the selected zones according to the population of each zone.

\section{Mukono}

Based on results of the urban survey, an estimated injury mortality rate of $2.2 / 1000$ persons/year was used to calculate the required sample size, allowing for a maximum error of $\pm 0.11 \%$. The minimum sample was 6805 .

DATA COLLECTION INSTRUMENTS AND METHODS The questionnaire had three sections: the first collected information about household characteristics; number of persons in the household, type of dwelling, types of energy used, views of the respondent on prevalent injuries, and feasibility of strategies for prevention. The second collected demographic details about each member of the household and whether they had suffered any injury or injury fatality. Those that had occurred in the five years preceding the survey were included. The third collected detailed information about each injury event reported. The respondent was the most responsible adult in the household. After establishing rapport and securing consent, interviewers explained "injury" using local words and then read a list of common external causes. Outcomes were classified into death, disability, or full recovery. To minimize bias, the recall period for fatal injuries was restricted
Table 2 Cause of injury by outcome: urban ( $n=10$ 982); results are number (\%)

\begin{tabular}{llll}
\hline Cause & $\begin{array}{l}\text { Fatal } \\
(n=119)\end{array}$ & $\begin{array}{l}\text { Disabling } \\
(n=312)\end{array}$ & $\begin{array}{l}\text { Recovered } \\
(n=478)\end{array}$ \\
\hline Traffic & $55(46)$ & $122(39)$ & $139(29)$ \\
Burns & $11(9)$ & $36(12)$ & $113(24)$ \\
Cuts/stabs & $1(0.8)$ & $21(7)$ & $73(15)$ \\
Blunt injury & $4(3)$ & $15(5)$ & $30(6)$ \\
Poison & $9(8)$ & $7(2)$ & $4(0.8)$ \\
Animal bites & $6(5)$ & $18(6)$ & $14(3)$ \\
Falls & $4(3)$ & $39(13)$ & $85(18)$ \\
Gunshots & $24(20)$ & $35(11)$ & $7(1)$ \\
Other & $5(4)$ & $19(6)$ & $13(3)$ \\
\hline
\end{tabular}

to five years, and for fully recovered injuries to six months. Classifications of causes of injuries were derived from the International Classification of Diseases, 10th edition, except for "blunt injuries" and "cuts/stabs".

The quantitative part of the questionnaire was precoded and the qualitative component was filled out in the local language. Translation and back translation were done, and data collectors underwent rigorous training in interviewing techniques.

DATA MANAGEMENT

Field supervisors reviewed completed questionnaires each day and checked them for accuracy.

Each field supervisor resurveyed 5\% of the households. The intrareader and inter-reader reliability for all key variables was high (Pearson's correlation coefficients: 0.99 and 0.97 respectively, $\mathrm{p}<0.001)$. One of the authors (DG) translated the narratives. Where appropriate, we compared the percentages using Fisher's exact test or the $\chi^{2}$ statistic. We defined a "severe injury" as one leading to either disability or death.

\section{Results}

Altogether 1673 households, with 7427 persons, were surveyed in the rural setting. Their average age was $20.1 \pm 17.1$ years, with $62 \%$ age 20 or younger. In the city, 2322 households with 10982 people were surveyed. Of these, 5257 (48\%) were males and 1900 (17\%) were children 5 years or younger. None of these characteristics varied significantly across the parishes or subcounties studied.

\section{INJURY OUTCOMES}

\section{Mukono}

Thirty four fatal injuries occurred in the five years preceding the survey (table 1), an annual injury rate of 92/100 000 persons. Fifty five persons had disabling injuries, a prevalence rate of $0.7 \%$. In addition, 575 fully recovered injuries occurred in the six months preceding our survey.

\section{Kawempe}

In the city, 119 fatal injuries were reported in the five years preceding the survey (table 2), an average annual mortality of 217/100 000 persons. A total of 312 disabilities due to injury were reported, giving a prevalence proportion of $2.8 \%$. Furthermore, 478 fully recovered injuries were reported for the six months before 
Table 3 Top three causes of injury by age: rural (Mukono); results are number (\%)

\begin{tabular}{|c|c|c|c|c|c|c|}
\hline \multirow{2}{*}{$\begin{array}{l}\text { Age group } \\
\text { (years) }\end{array}$} & \multicolumn{3}{|c|}{ Severe injuries } & \multicolumn{3}{|c|}{ Recovered injuries } \\
\hline & No & Top 3 causes & & No & Top 3 causes & \\
\hline \multirow[t]{3}{*}{$<10$} & 15 & Falls & $5(33)$ & \multirow[t]{3}{*}{182} & Burns & $45(25)$ \\
\hline & & Traffic & $4(27)$ & & Cuts/stabs & $42(23)$ \\
\hline & & Burns & $2(13)$ & & Falls & $36(20)$ \\
\hline \multirow[t]{3}{*}{$10-19$} & 17 & Burns & $5(29)$ & \multirow[t]{3}{*}{126} & Cuts/stabs & $36(29)$ \\
\hline & & Traffic & $3(18)$ & & Blunt & $24(19)$ \\
\hline & & Drowning & $3(18)$ & & Traffic & $17(13)$ \\
\hline \multirow[t]{3}{*}{$20-29$} & 17 & Traffic & $5(29)$ & \multirow[t]{3}{*}{103} & Cuts/stabs & $49(48)$ \\
\hline & & Cuts/stab & $3(18)$ & & Blunt & $21(20)$ \\
\hline & & Drowning & $3(18)$ & & Traffic & $16(16)$ \\
\hline \multirow[t]{3}{*}{$30-39$} & 11 & Traffic & $5(45)$ & \multirow[t]{3}{*}{84} & Cuts/stabs & $34(40)$ \\
\hline & & Falls & $2(18)$ & & Traffic & $19(23)$ \\
\hline & & Drowning & $2(18)$ & & Blunt & $17(20)$ \\
\hline \multirow[t]{3}{*}{$40-49$} & 7 & Traffic & $3(43)$ & \multirow[t]{3}{*}{40} & Cuts/stabs & $18(45)$ \\
\hline & & Cuts/stab & $2(29)$ & & Blunt & $6(15)$ \\
\hline & & Burns & $1(14)$ & & Traffic & $5(13)$ \\
\hline \multirow[t]{3}{*}{$\geqslant 50$} & 15 & Traffic & $5(33)$ & \multirow[t]{3}{*}{37} & Cuts/stabs & $17(46)$ \\
\hline & & Blunt & $4(27)$ & & Falls & $6(16)$ \\
\hline & & Cuts/stab & $3(20)$ & & Traffic & $5(14)$ \\
\hline \multirow[t]{3}{*}{ Not stated } & $\mathrm{n} / \mathrm{a}$ & \multirow[t]{3}{*}{$\mathrm{n} / \mathrm{a}$} & & \multirow[t]{3}{*}{3} & Falls & $1(33)$ \\
\hline & & & & & Cuts/stab & $1(33)$ \\
\hline & & & & & Blunt & $1(33)$ \\
\hline \multirow[t]{3}{*}{ Total } & 82 & Traffic & $25(30)$ & \multirow[t]{3}{*}{575} & Cuts/stabs & $196(34)$ \\
\hline & & Falls & $13(16)$ & & Blunt & 108 (19) \\
\hline & & Cuts/stab & $11(13)$ & & Falls & $72(13)$ \\
\hline
\end{tabular}

Table 4 Top three causes of injury by age: urban (Kawempe); results are number (\%)

\begin{tabular}{|c|c|c|c|c|c|c|}
\hline \multirow{2}{*}{$\begin{array}{l}\text { Age group } \\
\text { (years) }\end{array}$} & \multicolumn{3}{|c|}{ Severe injuries } & \multicolumn{3}{|c|}{ Recovered injuries } \\
\hline & \multirow{2}{*}{$\begin{array}{l}\mathrm{No} \\
58\end{array}$} & \multicolumn{2}{|l|}{ Top 3 causes } & \multirow{2}{*}{$\begin{array}{l}\text { No } \\
168\end{array}$} & \multicolumn{2}{|l|}{ Top 3 causes } \\
\hline \multirow[t]{3}{*}{$<10$} & & Burns & $24(41)$ & & Burns & $85(51)$ \\
\hline & & Traffic & $14(24)$ & & Falls & $31(19)$ \\
\hline & & Falls & $7(12)$ & & Cuts/stabs & $24(14)$ \\
\hline \multirow[t]{3}{*}{$10-19$} & 71 & Traffic & $25(35)$ & 90 & Traffic & $28(31)$ \\
\hline & & Falls & $1(15)$ & & Falls & $22(24)$ \\
\hline & & Burns & $8(11)$ & & Cuts/stabs & $20(22)$ \\
\hline \multirow[t]{3}{*}{$20-29$} & 126 & Traffic & $56(44)$ & 105 & Traffic & $48(46)$ \\
\hline & & Gunshots & $27(21)$ & & Cuts/stabs & $14(13)$ \\
\hline & & Animal bite & $10(8)$ & & Blunt & $13(12)$ \\
\hline \multirow[t]{3}{*}{$30-39$} & 96 & Traffic & $50(52)$ & 61 & Traffic & $27(44)$ \\
\hline & & Gunshots & $20(21)$ & & Falls & $12(20)$ \\
\hline & & Burns & $5(5)$ & & Cuts/stabs & $6(10)$ \\
\hline \multirow[t]{3}{*}{$40-49$} & 40 & Traffic & $19(48)$ & 25 & Traffic & $11(44)$ \\
\hline & & Gunshots & $6(15)$ & & Falls & $4(16)$ \\
\hline & & Falls & $4(10)$ & & Burns & $3(12)$ \\
\hline \multirow[t]{3}{*}{$\geqslant 50$} & 33 & Traffic & 11 (33) & 13 & Traffic & $4(39)$ \\
\hline & & Falls & $9(27)$ & & Falls & $4(39)$ \\
\hline & & Cuts/stab & $3(9)$ & & Cuts/stabs & $3(23)$ \\
\hline \multirow[t]{3}{*}{ Not stated } & 7 & Traffic & $2(29)$ & 16 & Cuts/stabs & $4(25)$ \\
\hline & & Burns & $1(14)$ & & Traffic & $3(19)$ \\
\hline & & Blunt & $1(14)$ & & Falls & $2(13)$ \\
\hline \multirow[t]{3}{*}{ Total } & 431 & Traffic & $117(27)$ & 478 & Traffic & $139(29)$ \\
\hline & & Gunshots & $59(14)$ & & Burns & $113(24)$ \\
\hline & & Burns & $47(11)$ & & Cuts/stabs & $73(15)$ \\
\hline
\end{tabular}

the survey. Injury rates for all three categories were higher in the city.

\section{OUTCOME BY CAUSE}

Mukono

The leading cause of fatal injuries was drowning $(27 \%)$, followed by traffic $(18 \%)$, and blunt injuries (15\%) (table 1). Traffic was the leading cause of disabling injuries (35\%), followed by falls $(24 \%)$, and cuts or stabs $(16 \%)$. A smaller proportion of disabling injuries was caused by burns and blunt injuries, each $11 \%$. The leading cause of fully recovered injuries was cuts or stabs (34\%), followed by blunt injuries (19\%), traffic $(13 \%)$, and falls $(13 \%)$.

\section{Kawempe}

In this setting, the leading cause of fatal injuries was traffic ( $46 \%)$, followed by gunshot wounds $(20 \%)$ (table 2$)$. Other causes included burns $(9 \%)$, poisoning $(8 \%)$, and animal bites $(5 \%)$. Traffic and burns were the leading causes of non-fatal injuries and traffic also accounted for $39 \%$ of all disabling injuries, and $29 \%$ of recovered injuries. Burns accounted for $12 \%$ of the disabling injuries and $24 \%$ recovered injuries.

In both settings, males were injured more often than females except for burns, cuts/stabs, and blunt injuries.

\section{INJURY OUTCOME BY AGE}

\section{Mukono}

Falls were the most common cause of severe injuries in children aged 10 years and younger, accounting for $33 \%$, followed by traffic $(27 \%)$, and burns (13\%) (table 3). In all age groups 20 years and older, traffic was the most important cause. Those 30-39 years were the most affected by traffic, followed by the 20-29 and 40-49 year age groups (29\% each).

Among fully recovered injuries, cuts/stabs were the most important cause in all age groups, except in children 10 years or younger, among whom burns were the most frequent cause. The age group most affected by cuts/stabs were $20-29$ years $(48 \%)$, followed by the $\geqslant 50$ and $40-49$ age groups $(46 \%$ and $45 \%$, respectively).

\section{Kawempe}

Burns were the leading cause of severe injuries in children 10 years or younger $(41 \%$ ) (table 4 ), while traffic was the leading cause among the rest. Among those 30-39 years, traffic accounted for $52 \%$ of the total, followed by gunshots among those 20-49 years (19\%).

The majority $(51 \%)$ of fully recovered injuries in children aged 10 years or younger were caused by burns. Traffic was again the most important cause of recovered injuries in all other age groups.

PLACE

Most injuries happened either at home or on roads. In the rural community, $29 \%$ (10) of the deaths happened at home and another $29 \%$ on roads. Forty five per cent of disabling injuries (25) were at home and 38\% (21) on the road. Forty six per cent (267) of recovered injuries occurred at home, and $22 \%$ (124) on the roads.

INTENT

In the rural setting, $21 \%$ (7) of the fatal injuries were intentional, whereas only $2 \%$ (1) of the disabling injuries and $12 \%$ (70) of the recovered injuries were intentional. In each injury outcome category, the majority were unintentional.

During the urban survey, "intent" for fatal injuries had not been incorporated in the questionnaire. However, for disabling injuries, 3\% 


\section{Key points}

- There are important differences in patterns of injury between urban and rural communities.

- Drowning comprises a large, mostly neglected problem in Uganda.

- Traffic injuries and deaths among young males require urgent action.

- A better understanding of childhood burns and falls will help identify modifiable factors.

were intentional, whereas $10 \%$ of fully recovered injuries were intentional. The rest of the injuries were either unintentional or intent could not be determined.

\section{Discussion}

There have been criticisms of the Global Burden of Disease Study results with regard to Asia, as government data sources, which are fairly accurate, were ignored. ${ }^{5}$ In Africa, the picture is even less clear, and the study estimates warrant skepticism as it relies heavily on South African data, which are likely to be unrepresentative. Most of the injury data from Africa are health facility based, yet formal health facility use is quite low in some countries. A Ghanian community based study found only $31 \%$ of fatal injuries received formal medical care. ${ }^{6}$ In such countries, therefore, surveillance at health facilities alone is inadequate to determine the magnitude, even of severe injuries.

A better data collection system is essential to understand the pattern of injury in Uganda, and should also provide some insight into injury patterns for other parts of East Africa. Although it is possible to begin some injury prevention activities without surveillance, if the burden is not better appreciated, injuries are often given a low priority and little or no resources allocated. ${ }^{78}$ Programs that are designed without using data may be inappropriate and their evaluation difficult.

This study found a high incidence of injury especially in the urban setting. It suggests that projections raised by the Global Burden of Disease Study concerning injury may be correct in at least one African country. It also demonstrates a high incidence of injury in young urbanites. This may indicate that the projections for an increase in rates with increased urbanization and proportion of young people may be true for Uganda.

The annual injury mortality rate of 92/ 100000 person years in the rural setting shows a huge injury burden, and the rate of $217 / 100000$ person years in the city is even worse. These rates are twice as high as the rates in Ghana, ${ }^{6}$ and the prevalence of disabling injury in urban Uganda was four times that in rural Uganda. In Ghana, all age injury mortality is estimated at $62 / 100000 /$ year, with a non-fatal rate of $7.56 / 100 /$ year. Part of this difference could be because Uganda's traffic injury rates are the worst in the region.

In most established market economies, injuries are the leading cause of death and of lost disability adjusted life years for those 1-19 years. Injury death rates in low income countries are higher than in industrialized countries. ${ }^{1}$ The probability of dying from an injury by age 19 is also much higher in the developing world than in the established market economies. This difference is most likely related to inadequate preventive measures and to poor medical care. Provisions for pedestrians and cyclists are minimal or nonexistent in spite of the fact that road traffic is the most important cause of injury in most of these countries.

One important difference between the urban and the rural populations was the higher rate of drowning in the rural community. This finding is consistent with findings from other studies in developing countries and is expected with greater exposure of rural people to unprotected water surfaces. In some rural areas of China and Sri Lanka a similar picture is seen, where drowning overtakes road traffic as a cause of unintentional injury. ${ }^{9}$ The Ugandan district surveyed has an extensive water surface, surrounded by fishing communities. Most fishing and water transport is in small nonmotorized boats and canoes. It is not known what proportion of the people in these communities can swim, there is no coast guard, and the boats are not equipped with any floatation or other rescue devices.

Road traffic injuries are a huge burden to this population. These results are consistent with the pattern reported from the Ugandan hospital trauma registries. ${ }^{10}$ The majority of persons involved in traffic injuries were cyclists. Although many studies in Africa have found pedestrians the largest group of injured road users, our finding emphasizes the greater plight of cyclists as vulnerable road users. It may also point to a transition in Africa, following the Asian pattern, where bicycles transport more people than do motor vehicles. ${ }^{11}$ In Uganda, the last 10 years have seen an explosive growth in the numbers of bicycles and motor cycles, especially the taxi cyclists (Uganda Revenue Authority reports, 1994-99). The much higher rates in the city may reflect more intense economic activity, resulting in heavier traffic, with an increased attempt to share the road by both fast motorized traffic and vulnerable road users. Other important factors in developing countries, like alcohol, poor driver skill, and poor road designs, were not assessed, but are likely to be contributors.

Falls were the second most common cause of severe injuries in both settings, occurring most often in those under 10. This may reflect high risk environments, such as lack of proper sleeping and play facilities, or inadequate supervision. In other developing countries, falls are an important cause of injury of boys and young adult males. ${ }^{12}$ In established market economies, falls have their most devastating effects among the elderly and infirm. ${ }^{13}{ }^{14}$ 
Burns were another important cause of morbidity and mortality in this survey. Domestic burns are a well documented problem in low income countries and in poor households in high income countries. ${ }^{15-18}$ In some industrialized countries, hot beverage spills, unregulated water heaters, and fires from space heaters are particular problems. In contrast, in Uganda, open cooking fires and crowded housing with no proper kitchens, or unsupervised play areas are likely to be more important risks. Stabs, cuts, and blunt injuries were the leading causes of minor injuries, and the majority occurred at home, $14 \%$ being intentional. This is low by developing country standards. ${ }^{19}$

In discussions with the health departments of the two districts, we found that injury prevention was not planned for and the resources used to treat injuries were not quantified. This is likely to be the case in other places where the emphasis remains infectious diseases.

\section{LIMITATIONS}

The major limitations were mainly related to definitions and severity ascertainment. Whereas "injury" is well described in the local language, disability is not. It is possible that some injuries reported as disabling would end in full recovery. This misclassification is accentuated by the six months cut off, since some injuries that would ultimately leave no disability, may have been viewed as disabling at the time of interview. Fatalities were likely to be accurately reported. Inclusions and exclusions of fatalities on either side of the five year cut off are likely to cancel out. Another likely source of misclassification is intent. Although the interviewers assured the respondents that this information was not for legal purposes, intentional injuries are likely to have been under-reported due to social stigma and criminal implications. Despite these limitations, we feel that these results are a good representation of the pattern.

\section{Implications for prevention}

Injuries, especially water and road traffic, are a large burden to the people of both Kawempe and Mukono. Drowning is a major and neglected problem for Mukono. Risk factor analysis and appropriate interventions are urgently needed. Health, transport, education, and other relevant sectors must work together to find ways of reducing this burden. Safety for vulnerable road users should be a priority. Where the mandate for health services delivery is decentralized, local authorities should be urged to integrate injury prevention in their plans.

This study was funded by the Canadian Network for International Surgery, and the International Clinical Epidemiology Network, to whom we are very grateful. We acknowledge ology Network, to whom we are very grateful. We acknowledge
the logistical support from the Mukono District Medical Office the logistical support from the
and Makerere Medical School.

1 Murray CJL, Lopez AD. Mortality by cause for eight regions of the world: Global Burden of Disease Study. Lancet 1997;349:1269-76.

2 Statistics Department (Uganda) and Micro International Statistics Department (Uganda) and Micro International
Inc. Uganda Demographic and Health Survey 1995. Claverton, MD; Statistics Department (Uganda) and Micro ton, MD; Statistics Depar
International Inc, 1996.

3 Louis MR, Richard AP. Designing and conducting survey research: a comprehensive guide. 2nd Ed. San Francisco: Jossey-Bass Publishers, 1997

4 Kish L. Survey sampling. New York: John Wiley \& Sons, 1965.

5 Mohan D. Injuries in less industrialized countries: what do we know? Inj Prev 1997;3:241-2.

6 Mock CN, nii-Amon-Kotei D, Maier RV. Low utilization of formal medical services by injured persons in a developing nation: health service data under estimates the importance of trauma. F Trauma 1997;42:504-13.

7 Zwi AB, Forjouh S, Murugusampillay S, et al. Injuries in developing countries: policy response needed now. Trans $R$ Soc Trop Med Hyg 1996;90:593-5.

8 Forjouh S, Zwi AB, Mock CN. Injury control in Africa: getting governments to do more. Trop Med Int Health 1998;5: ting gove.

9 Barss P, Smith GS, Baker SP, et al. Unintentional injuries: drowning, falls and burns. Injury prevention: an international perspecio. New York: Oxford International Press, 1998: $150-65$.

10 Andrews CN, Kobusingye OC, Lett RR. Road traffic accident injuries in Kampala. East Afr Med $\mathscr{f}$ 1998;76:18994.

11 Lowe MID. The bicycle: vehicle for a small planet. Washington, DC: Worldwatch Institute, 1989;90:1-62. (Worldwatch paper.)

12 Bangdiwala SI, Anzola-Perez E, Romer C, et al. Incidence of injuries in young people: I. Methodology and results of a collaborative study in Brazil, Chile, Cuba and Venezuela. Int 7 Epidemiol 1990;19:115-24.

13 Fife D, Barancik JI, Chatteijee MS. Northeastern Ohio Trauma Study: II: injury rates by age, sex and cause. $A m \mathcal{F}$ Public Health 1984;74:473-8.

14 Northridge ME, Nevitt MC, Kelsey JL, et al. Home hazards and falls in the elderly: the role of health and functional and falls in the elderly: the role of health
status. Am f Public Health 1995;85:509-15.

15 Baker SP, Fingerhut L, Higgins L, et al. Injury to children and teenagers: state by state mortality facts. Baltimore, MD: Johns Hopkins Center for Injury Research and Policy, 1996.

16 Bjerregaard P. Fatal non-intentional injuries in Greenland. Arctic Med Res 1992;51:22-6.

17 Muir BL. Health status of Canadian Indians and Inuit-1990. Ottawa, Canada: Indian and Northern Health Services, Medical Services Branch, Health and Welfare Canada, 1991: 1-58.

18 Courtright P, Haile D, Kohls E. The epidemiology of burns in rural Ethiopia. $\mathcal{F}$ Epidemiol Community Health 1993;47: 19-22.

19 Barss P, Smith G, Baker S, et al. Intentional injuries; homicide, suicide, and other violence. Injury prevention: an international perspective. New York: Oxford University Press, 1998:245-75. 